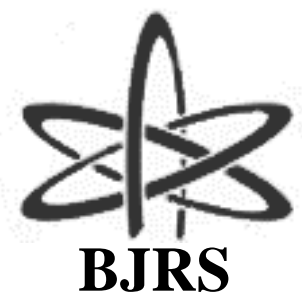

BRAZILIAN JOURNAL

$\mathrm{OF}$

RADIATION SCIENCES

07-02A (2019) 01-08

\title{
Validating a virtual source model based in Monte Carlo method for profiles and percent depth doses calculation
}

\author{
R. A. Del Nero, ${ }^{\mathrm{a}, *} ;$ M. V. N. Nakandakari ${ }^{\mathrm{b}} ;$ H. Yoriyaz ${ }^{\mathrm{a}}$ \\ ${ }^{a}$ Instituto de Pesquisas Energéticas e Nucleares (IPEN-CNEN / SP), Av. Professor Lineu Prestes, 2242 - Cidade \\ Universitária, 05508-000 Sao Paulo, Sao Paulo, Brazil \\ readelnero@usp.br \\ hyoriyaz@ipen.br \\ ${ }^{b}$ Hospital Beneficência Portuguesa de São Paulo, Rua Maestro Cardim, 769 - Bela Vista, \\ 01323-001 Sao Paulo, Sao Paulo, Brazil \\ marcos.sake@gmail.com
}

\begin{abstract}
The Monte Carlo method for radiation transport has been adapted for medical physics application. More specifically, it has received more attention in clinical treatment planning with the development of more efficient computer simulation techniques. In linear accelerator modeling by the Monte Carlo method, the phase space data file (phsp) is an alternative representation for radiation source. However, to create a phase space file and obtain good precision in the results, it is necessary detailed information about the accelerator's head and commonly the supplier does not provide all the necessary data. An alternative to the phsp is the Virtual Source Model (VSM). This alternative approach presents many advantages for the clinical Monte Carlo application. This is the most efficient method for particle generation and can provide an accuracy similar when the phsp is used. This research propose a VSM simulation with the use of a Virtual Flattening Filter (VFF) for profiles and percent depth doses calculation. Two different sizes of open fields $\left(40 \times 40 \mathrm{~cm}^{2}\right.$ and $40 \times 40 \mathrm{~cm}^{2}$ rotated $\left.45^{\circ}\right)$ were used and two different source to surface distance (SSD) were applied: the standard $100 \mathrm{~cm}$ and custom SSD of $370 \mathrm{~cm}$, which is applied in radiotherapy treatments of total body irradiation. The data generated by the simulation was analyzed and compared with experimental data to validate the VSM. This current model is easy to build and test.
\end{abstract}

Keywords: virtual source model, Monte Carlo method, radiotherapy. 


\section{INTRODUCTION}

During the 1970s, a considerable number of Monte Carlo codes were written for medical physics application. In 1976, Raeside published a review article showing the principles of this method and its first applications in medical physics. Since then, the number of publications in this field using the simulation of the transport of radiation continues to increase. In the last decades, the Monte Carlo method for radiation transport has been shown as very accurate and with a practical approach for photons and electrons simulations used in different applications in the medical physics field. For example, activities such as nuclear medicine, radiodiagnostic, radioactivity protection and radiotherapy, including dosimetry as well $[1,2]$.

The calculation for dose distribution is fundamental in the radiotherapy field to achieve expected results in the tumor's growth control without complications [3, 4]. Due some complex configurations like air or bones interfaces and irregular fields, the treatment planning systems (TPS) can not calculate with high precision the right dose distribution [5]. The Monte Carlo methods come up as a powerful tool to overcome these challenges because the code's capacity to perform radiation transport calculations for systems includes complex geometries [2].

For the dose calculation using the Monte Carlo method, it is very important to have available detailed information about the geometry and the materials of the accelerator head's components to achieve levels of simulation accuracy, which are reliable [6]. In this case, the electrons are injected one by one through the entrance window of the treatment head. Their way through the treatment head is tracked by a computer simulation to compose all the physical process of clinical significance [7].

When all the information of the accelerator head is available and the simulation is performed, the data output is stored for each and every particle in a phase space data file (phsp) which includes the charge, energy, position, direction and particle type information. This phsp also contains a tag about the history of the particle as well as where the particle is originated from [8,9].

A phsp is a collection of pseudo-particles emerging from a source of radiation used for radiotherapy treatment. Each of these pseudo-particles is tagged so it is recorded only once when passing through the surface of interest. Simply put, the same particle is not recorded beyond the point of interest 
where it was measured [10]. The term pseudo-particles is used here as a representative of the average "real" physical particles from the source. These Monte Carlo particles or pseudo-particles have statistical "weights" used for sampling in the simulation process.

However, the information about the accelerator often does not present sufficient details to ensure accuracy of the simulation. Therefore, a different approach was developed: the phsp can be substituted by the beam modelling [8].

Studies have demonstrated that the beam modelling could save computational time and drastically reduce file occupation in disk. The Monte Carlo simulations can be more efficient with source model than phsp [7, 11].

It is known that the absorbed dose depends of the initial energy spectrum for the primary photons as well as secondary particles, both generated in the accelerator head and in the target. Nonetheless, it is possible to make a system to simulate the same deposited energy without making explicit the original geometry of the accelerator head. This procedure is called Virtual Source Model (VSM) [7, 12].

The first step is to make an appropriate representation of the beam for a determined design of the treatment head. The beam representation is the brief mathematical description of the phsp [7, 12]. This model optimizes many parameters in order to obtain good deposited doses approximation. Thereby, the main advantage of using a VSM is the reduced time because it is a faster procedure when compared with the classical Monte Carlo simulation.

This research shows a study about VSM with the addition of a Virtual Flattening Filter (VFF) as based on Rucci et al. [13, 14]. This setup will be used in more advanced dosimetry algorithms for doses calculation in total body irradiation technique. However, to these advances become reality, some introduced challenges need to be overcome, because each parameter utilized for the dose calculation must be measured and validated before using in clinical routine.

Thus, the objective of this work consists of simulating a VSM with a VFF for profiles and percent depth doses (PDDs) calculation for open fields $\left(40\right.$ x $40 \mathrm{~cm}^{2}$ and 40 x $40 \mathrm{~cm}^{2}$ rotated $\left.45^{\circ}\right)$, using standard source to surface distance (SSD) of $100 \mathrm{~cm}$ and custom SSD of $370 \mathrm{~cm}$ applied in radiotherapy treatments of total body irradiation. The simulations were compared with experimental data to validate the VSM. 


\section{MATERIALS AND METHODS}

\subsection{EXPERIMENT}

To obtain the experimental results, it was used the single energy Varian Unique Medical Linear Accelerator (6 MV), from the Beneficência Portuguesa Hospital located in São Paulo city, Brazil. A simulator phantom Oxigen (OXDOS01-01) was used for absolute dosimetry in water, measuring 30 x $30 \times 40 \mathrm{~cm}^{3}$ constructed in $10 \mathrm{~mm}$ thick crystal acrylic, including a camera positioning tower (OXDOS01-10).

It was also used an ionization chamber PTW-Freiburg, farmer type chamber $0.6 \mathrm{~cm}^{3}$, waterproof. The ionization chamber calibration set and the experimental part reached a global error of $1.5 \%$ for all experiments [15].

The experimental data for the profiles and PDDs were obtained for open field, that is $40 \mathrm{x} 40 \mathrm{~cm}^{2}$ using standard SSD of $100 \mathrm{~cm}$ and $40 \times 40 \mathrm{~cm}^{2}$ field positioned diagonally, that is $40 \mathrm{x} 40 \mathrm{~cm}^{2}$ rotated $45^{\circ}$ using custom SSD of $370 \mathrm{~cm}$ applied in radiotherapy treatments of total body irradiation.

\subsection{VIRTUAL SOURCE MODEL (VSM)}

The parameters used in this part were based in previous work found in the literature [13, 14], with minor adjustments in order to improve the comparison between the experimental and simulated data.

The whole computational simulation part was made with the MCNP6 code [16]. The number of histories (nps) adopted was $2 \times 10^{10}$, keeping, in this case, the statistical uncertainty below $1.84 \%$ for SSD $100 \mathrm{~cm}$ and $3.47 \%$ for SSD $370 \mathrm{~cm}$.

Dose calculation in MCNP6 has been performed scoring the energy deposited by the radiation in small volume targets along the medium depth. The MCNP6 *F8 tally option, chosen by the user, provides the energy deposited in each target in $\mathrm{MeV}$ which is divided by the target mass, giving the dose values in $\mathrm{MeV} / \mathrm{g}$. 
A primary source with dimensions of $1 \times 1 \mathrm{~cm}^{2}$ was simulated. As mentioned in previous work by Rucci et al. [13, 14], the energy spectrum considered is a superposition of three monoenergetic sources with energies of $1 \mathrm{MeV}, 3 \mathrm{MeV}$ and $5 \mathrm{MeV}$ with respective probabilities of $76.36 \%$, $19.36 \%$ and $4.28 \%$. According to these authors, several empirical tests were performed to achieve the best energy values to obtain the correct PDDs curves that match the experimental data.

The cut-off energy used for electrons and photons was, respectively, $1 \times 10^{5} \mathrm{eV}$ and $1 \times 10^{4} \mathrm{eV}$ [14]. Source divergence was set to $11.3^{\circ}$ for $40 \mathrm{x} 40 \mathrm{~cm}^{2}$ field and $13.85^{\circ}$ for $40 \times 40 \mathrm{~cm}^{2}$ field rotated $45^{\circ}$.

For SSD of $100 \mathrm{~cm}$, dose deposition was calculated in a $50 \times 50 \times 50 \mathrm{~cm}^{3}$ water phantom for PDDs and $60 \times 60 \times 50 \mathrm{~cm}^{3}$ water phantom for profiles. In the configuration of $370 \mathrm{~cm} \mathrm{SSD,} \mathrm{dose}$ deposition was calculated in a $200 \times 200 \times 50 \mathrm{~cm}^{3}$ water phantom.

Due the high energy X-ray photons intensity generated by bremsstrahlung in linear accelerator, as well as the non uniformity of these photons, it is added a flattening filter in the beam line. This flattening filter is added so the beam profile can have an uniformity when there is a large treatment field, normally up to $40 \times 40 \mathrm{~cm}^{2}$ [17].

Once the flattening filter is removed from the X-ray beam's way, the dose rate increases. Another effect when removed is the reduction in head scattering because the flattening filter causes the dispersion of photons [18].

In this work, it was proposed a simple approach of a VFF made of copper. The modeled VFF is constituted of a circular cone of $1.1 \mathrm{~cm}$ radius and variable height: for $100 \mathrm{~cm} \mathrm{SSD}$ it was used 0.17 $\mathrm{cm}$ and for $370 \mathrm{~cm} \mathrm{SSD,} 0.12 \mathrm{~cm}$. The VFF modeling was made on top of a circular cylinder of 1.5 radius and thickness of $0.125 \mathrm{~cm}$. The VFF base was positioned $12.5 \mathrm{~cm}$ away from the primary virtual source. A simple representation of the VFF can be seen in Figure 1 and the whole design of the simulation can be observed in Figure 2. Note: figures not drawn to scale. 
Figure 1: Scheme of the Virtual Flattening Filter (VFF)

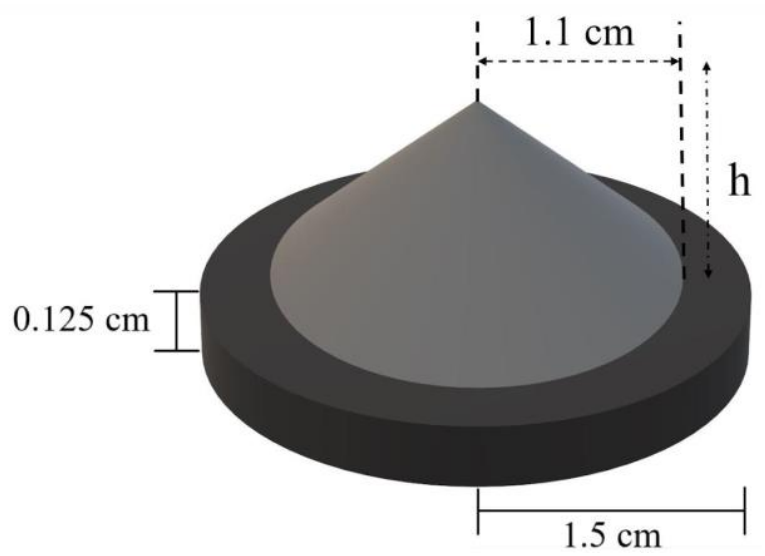

Figure 2: Virtual Flattening Filter (VFF) added to the Virtual Source Model (VSM) scheme used in the simulations

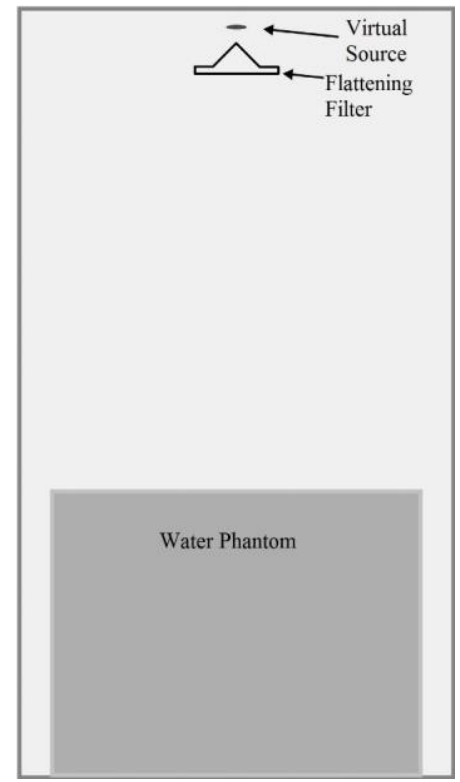

\subsection{ANALYZES}

To compare and overlap the simulated and experimental curves, the data was normalized according to the highest reading, which was considered as $100 \%$. This excludes the profile curves for $370 \mathrm{~cm}$ 
of distance because this methodology is not applied. In these cases, to obtain better overlapping curves, the values normalization was done from the average of the readings between 0 to $60 \mathrm{~cm}$ of distance from central radius.

\section{RESULTS AND DISCUSSION}

\subsection{SOURCE TO SURFACE DISTANCE (SSD) OF $100 \mathrm{~cm}$}

Firstly, PDDs and profiles for $100 \mathrm{~cm}$ depth for field size of $40 \mathrm{x} 40 \mathrm{~cm}^{2}$ are shown below. For interpolation, five different points among the distance variance were chosen and a difference average between experimental and simulated values was calculated from them.

According to Figure 3, which represents the comparison between PDDs, the statistical uncertainty of the Monte Carlo method was kept below 1.07\% and for interpolation the difference average between the experimental and simulated values was $2.62 \%$.

Next, the profile curves were analyzed. In these cases, the statistical uncertainty of the Monte Carlo method stayed below $1.84 \%$ and for interpolation, the difference of averages between experimental and simulated values was $1.97 \%$ for $1.5 \mathrm{~cm}$ depth, $2.10 \%$ for $5.0 \mathrm{~cm}, 1.98 \%$ for $10.0 \mathrm{~cm}$ and $1.03 \%$ for $20.0 \mathrm{~cm}$. It can be seen in Figures 4 to 7, respectively.

For all graphs, the curves plotted are very similar as it can be observed. 
Figure 3: Comparison between experimental and VSM PDDs, $40 \times 40 \mathrm{~cm}^{2}$ field

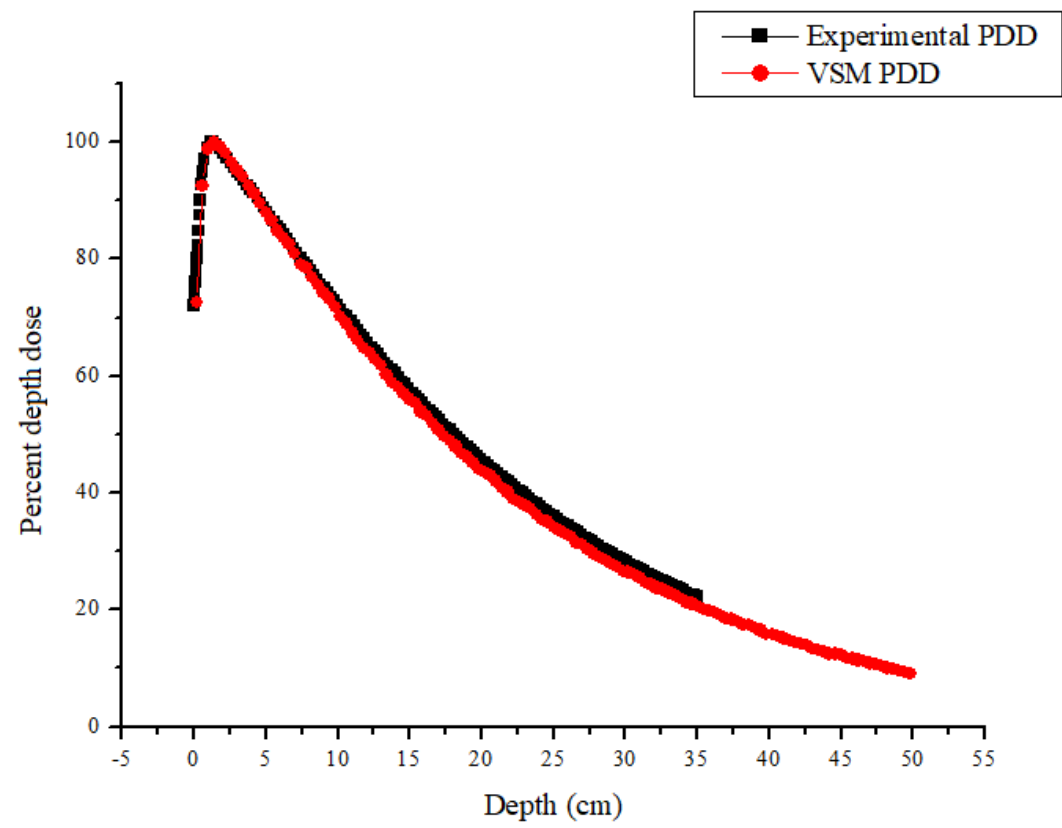

Figure 4: Profiles comparison between the experimental and VSM for a depth of $1.5 \mathrm{~cm}, 40 \times 40$ $\mathrm{cm}^{2}$ field

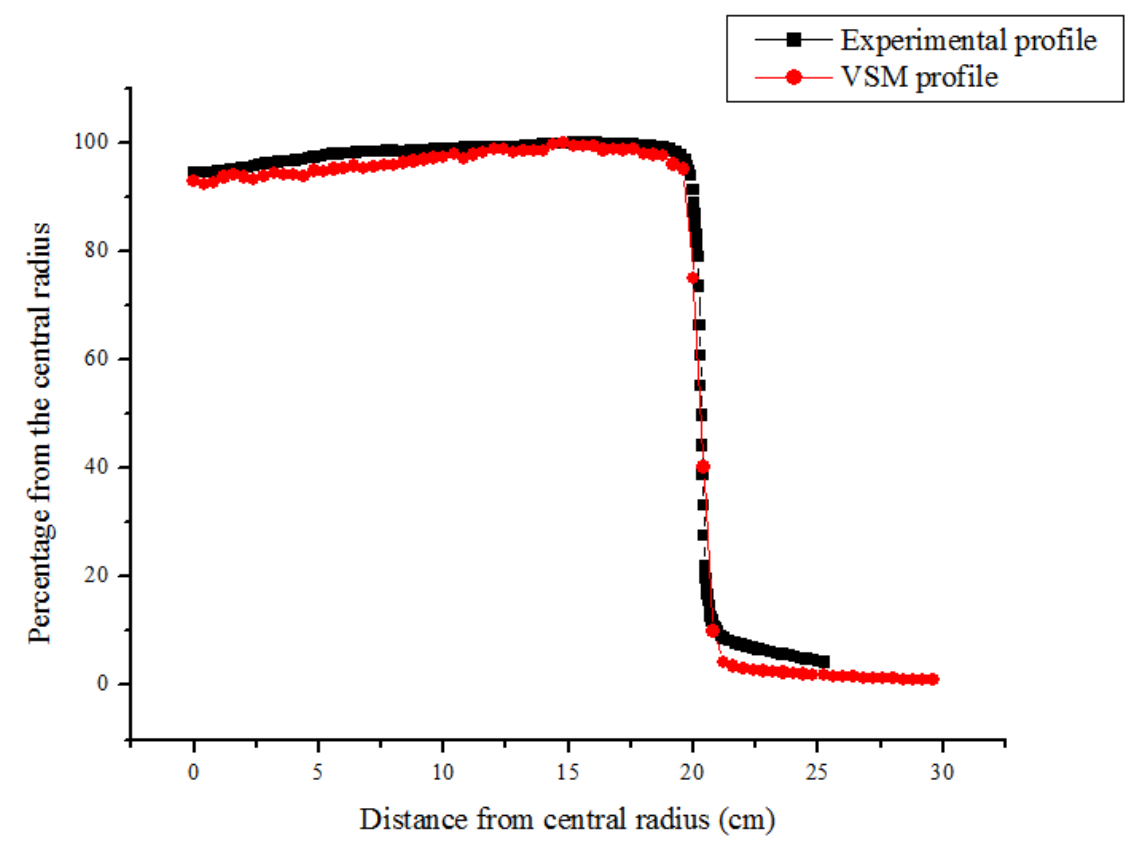


Figure 5: Profiles comparison between the experimental and VSM for a depth of $5.0 \mathrm{~cm}, 40 \times 40$ $\mathrm{cm}^{2}$ field

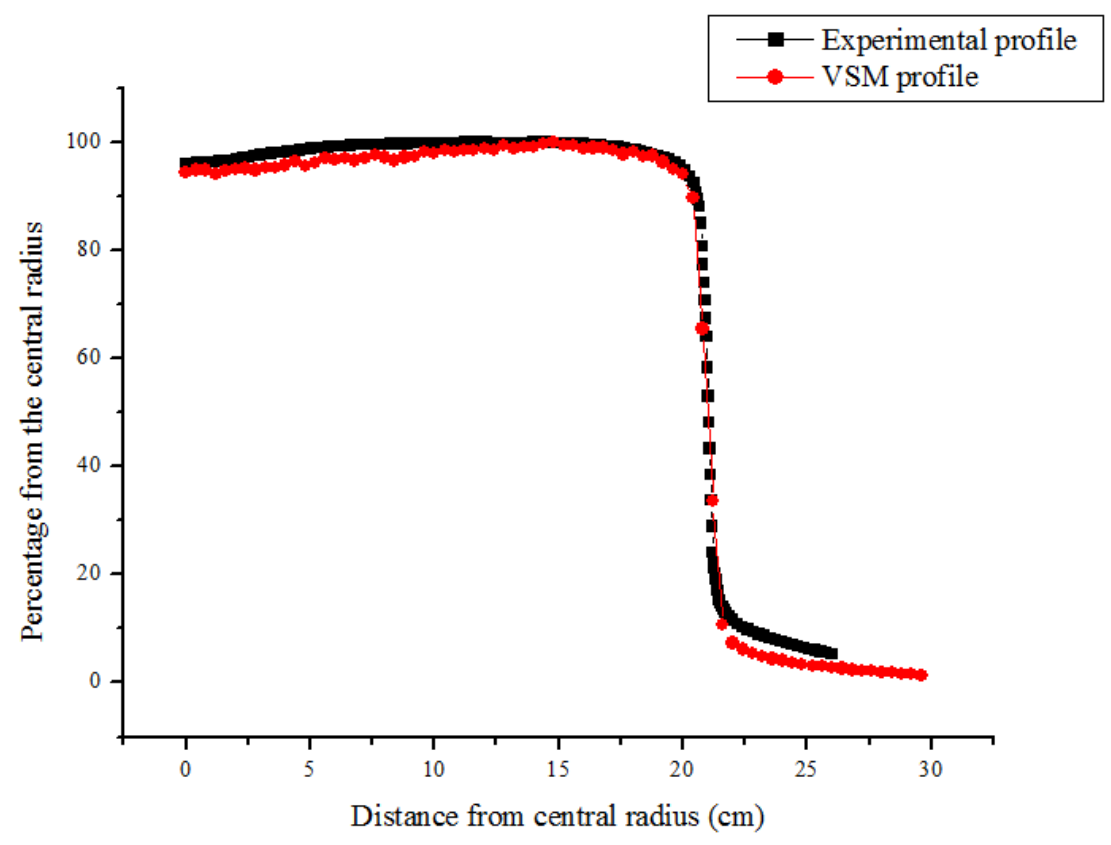

Figure 6: Profiles comparison between the experimental and VSM for a depth of $10.0 \mathrm{~cm}, 40 \times 40$ $\mathrm{cm}^{2}$ field

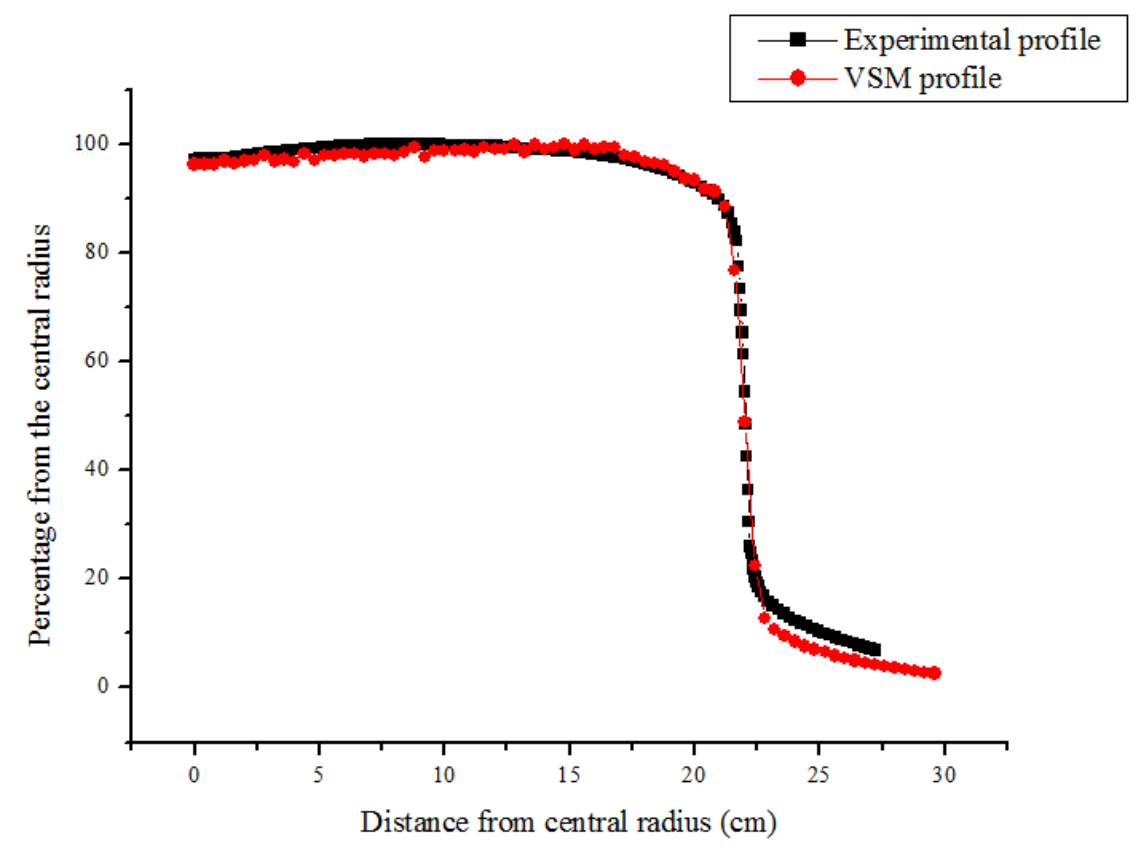


Figure 7: Profiles comparison between the experimental and VSM for a depth of $20.0 \mathrm{~cm}, 40 \times 40$ $\mathrm{cm}^{2}$ field

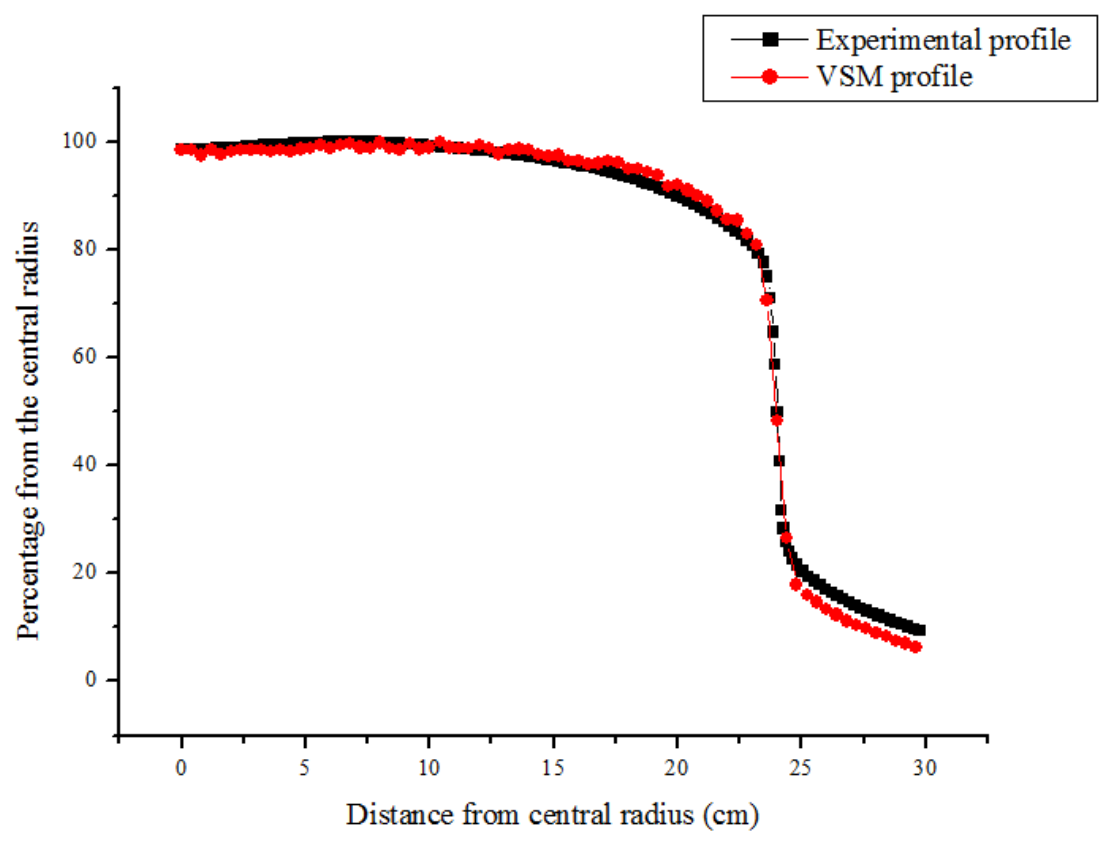

\subsection{SOURCE TO SURFACE DISTANCE (SSD) OF $370 \mathrm{~cm}$}

In the next step, the data for PDDs and profiles for field size of $40 \times 40 \mathrm{~cm}^{2}$ rotated $45^{\circ}$ and SSD $370 \mathrm{~cm}$ depth were studied. Again, for interpolation, it was calculated the difference average between the experimental and simulated values.

Figure 8 shows the comparison between experimental and simulated PDDs curves. The maximum statistical uncertainty of the Monte Carlo simulation and measurement error are respectively, 3.47\% and 1.5\%. Quantitative analysis has shown an average difference of $2.20 \%$ between the curves, demonstrating good agreement.

Figures 9 and 10 present the comparison of measured and calculated profile curves, respectively at depths of 5.0 and $10.0 \mathrm{~cm}$. In these cases, the statistical uncertainty of the Monte Carlo method was kept below $1.38 \%$. The average difference between the experimental and simulated values was $1.61 \%$ for $5.0 \mathrm{~cm}$ depth and $1.21 \%$ for $10.0 \mathrm{~cm}$ depth. 
Figure 8: Comparison between experimental and VSM PDDs, $40 \times 40 \mathrm{~cm}^{2}$ rotated $45^{\circ}$ field

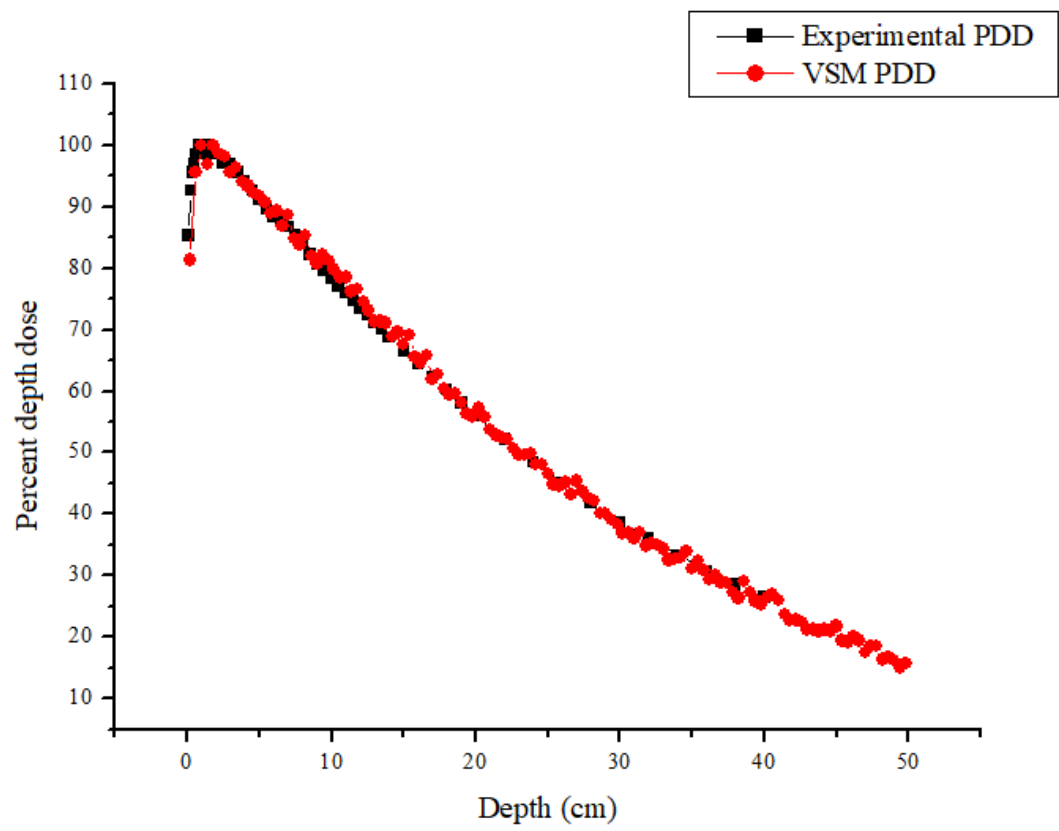

Figure 9: Profiles comparison between the experimental and VSM for a depth of $5.0 \mathrm{~cm}, 40 \times 40$ $\mathrm{cm}^{2}$ rotated $45^{\circ}$ field

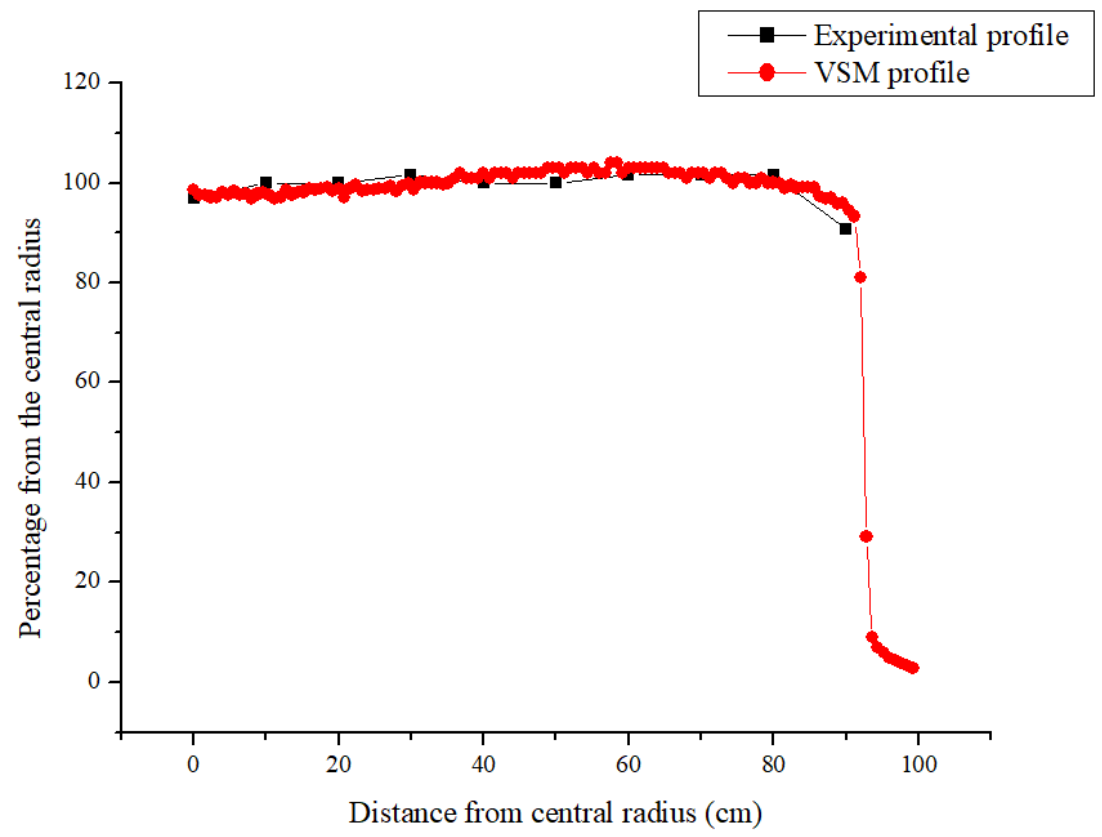


Figure 10: Profiles comparison between the experimental and VSM for a depth of $10.0 \mathrm{~cm}, 40 \times 40$ $\mathrm{cm}^{2}$ rotated $45^{\circ}$ field

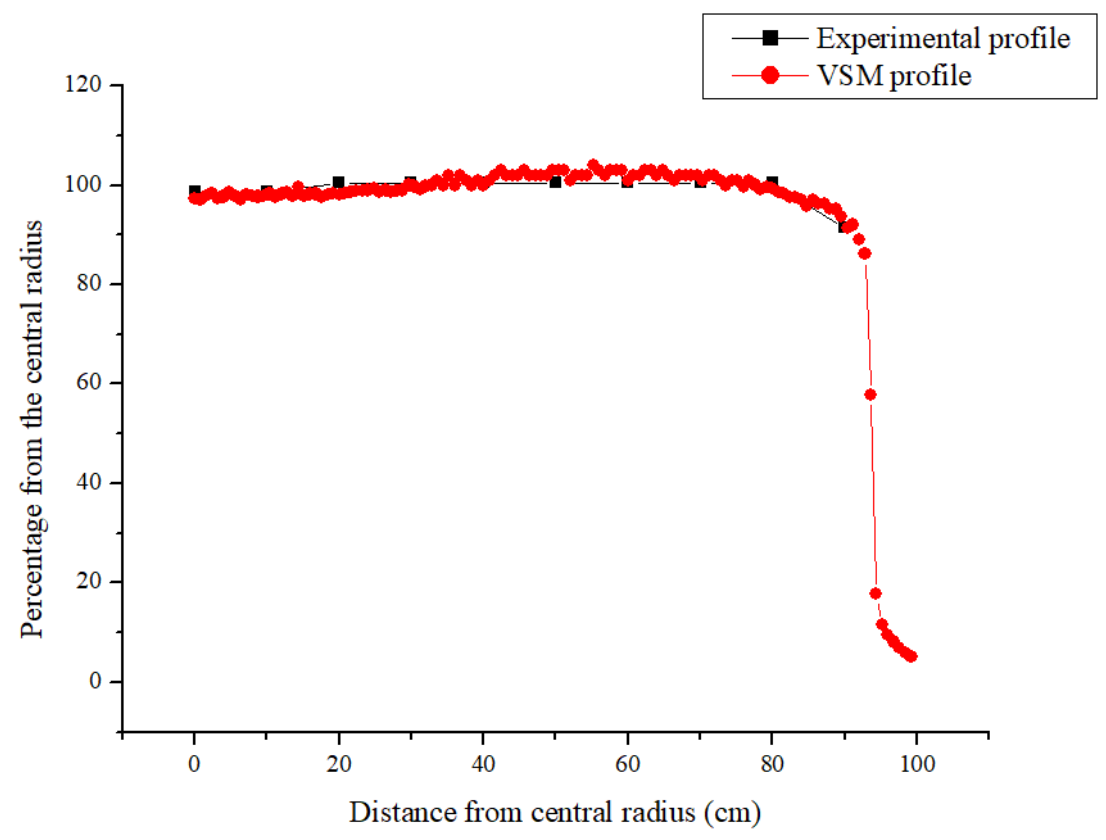

The photon beams of the linear accelerators produce electron contamination dose component and as the field size increases this contamination component by electrons increases [19]. Thus, since the electron contamination is not totally considered in this model, it is expected that this factor has contributed to the small differences found in this work.

Analyzing the superpositioning of the curves for the PDDs and profiles in different depths of the measurement in different field sizes, as well as the respectively experimental and statistical errors, it is possible to validate the proposal for the VSM usage.

\section{CONCLUSION}

Based on previous studies, in this work, a simple VSM for a $6 \mathrm{MeV}$ photon beams to be used in a non-conventional accelerator like total body irradiation was built. Some adjustments were necessary 
in order to improve the comparison with experimental data. For a better performance, a VFF was added.

The results of the simulation validate the model and suggest that this simple VSM can be made to substitute the lack of information about detailed shape of the accelerator's head and to the constituent materials of different accelerator models.

Finally, in the future, it will be possible the creation of a database for different field sizes. With the parameters here considered, it is possible to develop new VSMs for many field sizes. Besides, the VSM for field of $40 \times 40 \mathrm{~cm}^{2}$ size rotated $45^{\circ}$ will be used in more advanced dosimetry algorithms for dose calculation in total body irradiation techniques.

\section{ACKNOWLEDGMENT}

The authors acknowledge CAPES for supporting one of the authors $(*)$.

\section{REFERENCES}

1. ANDREO, P. Monte Carlo techniques in medical radiation physics. Physics in Medicine \& Biology, v. 36, n. 7, p. 861-920, 1991.

2. CHAVES, A.; LOPES, M. C.; AlVES, C. C.; OlIVERA, C.; PERALTA, L.; RODRIGUES, P.; TRINDADE, A. A Monte Carlo multiple source model applied to radiosurgery narrow photon beams. Medical Physics, v. 31, n. 8, p. 2192-2204, 2004.

3. AALTONEN, P.; BRAHME, A.; LAX, I.; LEVERNES, S.; NASLUND, I.; REITAN, J. B.; TURESSON, I. Specification of dose delivery in radiation therapy. Acta Oncologica, v. 36, p. 1$32,1997$.

4. ICRU - International Commission on Radiation Units and Measurements. Prescribing, recording and reporting photon beam therapy. ICRU Report 62 (supplement to ICRU Report 50). Bethesda: ICRU; 1999. 
5. PlESSIS, F. C. P. DU; WILLEMSE, C. A.; LÖTTER, M. G.; GOEDHALS, L. Comparison of Batho, ETAR and Monte Carlo dose calculation methods in CT based patients models. Medical Physics, v. 28, n. 4, p. 582-589, 2001.

6. SIKORA, M.; ALBER, M. A virtual source model of electron contamination of a therapeutic photon beam. Physics in Medicine \& Biology, v. 54, n. 24, p. 7329-7344, 2009.

7. MA, C. M.; FADDEGON, B. A.; ROGERS, D. W. O.; MACKIE, T. R. Accurate characterization of Monte Carlo calculated electron beams for radiotherapy. Medical Physics, v. 24, n. 3, p. 401-416, 1997.

8. YANG, J.; LI, J. S.; QUIN, L.; XIONG, W.; MA, C. M. Modelling of electron contamination in clinical photon beams for Monte Carlo dose calculation. Physics in Medicine \& Biology, v. 49, n. 12, p. 2657-2673, 2004.

9. VERHAEGEN, F.; SEUNTJENS, J. Monte Carlo modeling of external radiotherapy photon beams. Physics in Medicine \& Biology, v. 48, n. 21, p. 107-164, 2003.

10. CAPOTE, R.; JERAJ, R.; MA, C. M.; ROGERS, D. W. O.; SÁNCHEZ-DOBLADO, F.; SEMPAU, J.; SEUNTJENS, J.; SIEBERS, J. V. Phase-space database for external beam radiotherapy. International Nuclear Data Committee: summary report of a consultants' meeting. Vienna: International Atomic Energy Agency; 2006.

11. MA, C. M. Characterization of computer simulated radiotherapy beams for Monte Carlo treatment planning. Radiation Physics and Chemistry, v. 53, n. 3, p. 329-344, 1998.

12. SIKORA, M.; DOHM, O.; ALBER, M. A virtual photon source model of an Elekta linear accelerator with integrated mini MLC for Monte Carlo based IMRT dose calculation. Physics in Medicine \& Biology, v. 52, n. 15, p. 4449-4463, 2007.

13. RUCCI, A.; CARLETTI, C.; CRAVERO, W.; STRBAC, B. Use of IAEA's phase-space files for the implementation of a clinical accelerator virtual source model. Physica Medica, v. 30, n. 2, p. 242-248, 2014.

14. RUCCI, A.; CARLETTI, C.; CRAVERO, W.; STRBAC, B. Use of IAEA's phase-space files for virtual source model implementation: extension to large fields. Physica Medica, v. 32, n. 8, p. 1030-1033, 2016.

15. ANDREO, P.; BURNS, D. T.; HOHLFELD, K.; HUQ, M. S.; KANAI, T.; LAITANO, F.; SMYTH, V.; VYNCKIER, S. Absorbed dose determination in external beam radiotherapy: an 
international code of practice for dosimetry based on standards of absorbed dose to water. Vienna: International Atomic Energy Agency TRS-398; 2000.

16. PELOWITZ, D. B. (Editor); GOORLEY, J. T.; JAMES, M. R.; BOOTH, T. E.; BROWN, F. B.; BULL, J. S.; COX, L. J.; DURKEE, J. W.; ELSON, J. S.; FENSIN, M. L.; FORSTER, R. A.; HENDRICKS, J. S.; HUGHES, H. G.; JOHNS, R. C.; KIEDROWSKI, B. C.; MARTZ, R. L.; MASHNIK, S. G.; McKINNEY, G. W.; PRAEL, R. E.; SWEEZY, J. E.; WATERS, L. S.; WILCOX, T. A.; ZUKAITIS, A. MCNP6 ${ }^{\text {TM }}$ user's manual - Version 1.0. LA-CP-13-00634, Rev. 0. Los Alamos National Security, LLC, 2013.

17. PÖNISCH, F.; TITT, U.; VASSILIEV, O. N.; KRY, S. F.; MOHAN, R. Properties of unflatted photon beams shaped by a multileaf collimator. Medical Physics, v. 33, n. 6, p. 17381746, 2006.

18. JAVEDAN, K.; FEYGELMAN, V.; ZHANG, R. R.; MOROS, E. G.; CORREA, C. R.; TROTTI, A.; LI, W.; ZHANG, G. G. Monte Carlo comparison of superficial dose between flattening filter free and flattened beams. Physica Medica, v. 30, n. 4, p. 503-508, 2014.

19. BUTSON, M. J.; MATHUR, J. N.; METCALFE, P. E. Skin dose from radiotherapy X-ray beams: the influence of energy. Journal of Medical Imaging and Radiation Oncology, v. 41, n. 2, p. $148-150,1997$. 